\section{Vapor Phase Hydrogen Peroxide Inhibits Postharvest Decay of Table Grapes}

\author{
Charles F. Forney', Roger E. Rij', Ricardo Denis-Arrue ${ }^{2}$, and \\ Joseph L. Smilanick ${ }^{4}$ \\ Horticultural Crops Research Laboratory, Agricultural Research Service, \\ U.S. Department of Agriculture, 2021 South Peach Avenue, Fresno, \\ CA 93727
}

Additional index words. packaging, flush, Vitis vinfera, Botrytis cinerea

Abstract. The potential use of vapor phase hydrogen peroxide (VPHP) to prevent decay caused by Botrytis cinerea Pers. ex Fr. in table grapes (Vitis vinifera L.) was investigated. 'Thompson Seedless' and 'Red Globe' grapes, inoculated with Botrytis cinerea spores, were placed in polyethylene bags and flushed for 10 minutes with VPHP generated from a $30 \%$ to $35 \%$ solution of liquid hydrogen peroxide at $40 \mathrm{C}$. Immediately after treatment, bags were sealed and held at $10 \mathrm{C}$. Vapor phase hydrogen peroxide significantly reduced the number of terminable Botrytis spores on grapes. The number of terminable spores on 'Thompson Seedless' and 'Red Globe' grapes had been reduced $81 \%$ and $62 \%$, respectively, 24 hours following treatment. The incidence of decay on inoculated 'Thompson Seedless' and 'Red Globe' grapes was reduced 33\% and 16\%, respectively, after 8 days of storage at $10 \mathrm{C}$ compared with control fruit. Vapor phase hydrogen peroxide reduced the decay of noninoculated 'Thompson Seedless' and 'Red Globe' grapes $73 \%$ and $28 \%$, respectively, after 12 days of storage at 10C. Treatment with VPHP did not affect grape color or soluble solids content.

Botrytis cinerea is the principal postharvest pathogen of table grapes in California (Nelson, 1985) and is responsible for most of the losses that occur during storage. Decay of table grapes during refrigerated storage is controlled by periodic fumigation with sulfur dioxide (Harvey and Uota, 1978; Nelson, 1983). Grapes can be held for as long as 5 months using these procedures. Recently, however, there have been concerns about the presence of sulfite residues on fumigated grapes and their potentially adverse effects on sulfite-sensitive individuals (Federal Registry, 1986). This finding has resulted in the Environmental Protection Agency establishing a 10-ppm tolerance for sulfite in table grapes (Federal Registry, 1989). Current commercial fumigation practices result in residues that occasionally exceed this tolerance (Smilanick et al., 1990). Therefore, alternative methods to control decay in stored table grapes are needed.

Hydrogen peroxide $\left(\mathrm{H}_{2} \mathrm{O}_{2}\right)$ effectively kills microorganisms. Liquid $\mathrm{H}_{2} \mathrm{O}_{2}$ is effective in killing bacterial spores, especially at elevated temperatures and concentrations (Ito et al., 1973; Smith and Brown, 1980; von Bockelmann and von Bockelmann, 1972).

Received for publication 11 Mar. 1991. The authors wish to thank Kash Inc. for generously supplying the grapes used in this study. The cost of publishing this paper was defrayed in part by the payment of page charges. Under postal regulations, this paper therefore must be hereby marked advertisement solely to indicate this fact.

'Plant Physiologist.

${ }^{2}$ Agricultural Marketing Specialist.

${ }^{3}$ Research Technician.

${ }^{4}$ Research Plant Pathologist.
Currently, $\mathrm{H}_{2} \mathrm{O}_{2}$ solutions are used to sterilize plastic liners used in aseptic packages (Toledo, 1988). In recent years, vapor phase hydrogen peroxide (VPHP) has been shown to be effective in sterilizing plastic and stainless steel surfaces Klapes and Vesley, 1990; Wang and Toledo, 1986a, 1986b). The proportion of inactivated spores of Bacillus subtilis var. niger reached $99.9999 \%$ in $<10$ min when exposed to $1.131 \mathrm{mg} \mathrm{VPHP} /$ liter at 40C (Wang and Toledo, 1986b). The use of VPHP as a surface sterilant on food commodities has been suggested Klapes and Vesley, 1990), but there has been no report of its rise on fresh fruits or vegetables.

The objectives of this study were to 1) determine the effect of VPHP on the viability of Botrytis cinerea spores inoculated on the surface of grapes, and 2) measure the effect

Botrytis cinerea spores were grown on potato dextrose agar (PDA) at 20C for 1 to 2 weeks. Spores from four plates were removed by carefully rubbing the surface of the PDA with a sterile glass rod and rinsing with several drops of $0.01 \%$ Triton X-10O in sterile water. The rinses were passed through two layers of cheese cloth and diluted to 1 liter. Spores from one suspension were used to inoculate all grapes in a given experiment. The concentration of spores in the suspensions was determined with a hemocytometer and ranged from $5 \times 10^{6}$ to $10^{7}$ spores $/ \mathrm{ml}$. Field packed, nonfumigated 'Thompson Seedless' or 'Red Globe' grapes were obtained a day before the experiment and held at room temperature overnight to allow the grapes to warm. These cultivars were selected for their color difference to compare the effect of $\mathrm{H}_{2} \mathrm{O}_{2}$ on lightly and heavily pigof VPHP on the decay and quality of grapes. mented grapes. Grapes for the spore germination tests were rinsed with distilled water and allowed to dry before inoculation. Bunches of grapes were sprayed with the spore suspension to runoff. They were then placed in a $40 \mathrm{C}$ room for 1 to $2 \mathrm{~h}$ before treatment with VPHP at 40C.

Grape bunches weighing 300 to $600 \mathrm{~g}$ were individually placed into polyethylene bags (25 $\mu \mathrm{m}$ thick). A flush-vat machine (Model 30, Packaging Aid Corp., San Rafael, Calif.) was used to apply all VPHP and water vapor (control) treatments. Vapor phase hydrogen peroxide or water vapor was introduced into the bags by the procedure of Wang and Toledo (1986a). Air passed through a coppercoil heat exchanger to maintain $40 \mathrm{C}$, then bubbled via air stones through two $1000-\mathrm{ml}$ jars, each containing $250 \mathrm{ml}$ of $30 \%$ to $35 \%$ $\mathrm{H}_{2} \mathrm{O}_{2}$ or water. Jars were kept in a $40 \mathrm{C}$ water bath to assure good temperature control. The resulting concentration of peroxide vapor was $\approx 1.1 \mathrm{mg} \cdot \mathrm{liter}^{-1}$ of air based on the saturation concentration of $\mathrm{H}_{2} \mathrm{O}_{2}$ in air bubbled through a $35 \% \mathrm{H}_{2} \mathrm{O}_{2}$ solution at $40 \mathrm{C}$. This concentration of $\mathrm{H}_{2} \mathrm{O}_{2}$ was effective in killing spores of Bacillus subtilis (Wang and Toledo, 1986a) and was therefore chosen for treating spores of Botrytis cinerea. A flow rate of $3000 \mathrm{ml} \cdot \mathrm{min}^{-1}$, equivalent to more than two complete displacements of the bag volume per rein, was used (Wang and Toledo, 1986b). Bags of grapes were flushed for $10 \mathrm{~min}$ with VPHP or water vapor, sealed, and held at $10 \mathrm{C}$ until evaluated.

Spore terminability was determined by washing spores from inoculated grape bunches with $100 \mathrm{ml}$ of sterile distilled water 1,6 , or $24 \mathrm{~h}$ following treatment. A $10-\mathrm{ml}$ aliquot of this rinse was centrifuged for $4 \mathrm{~min}$ at $1000 \mathrm{x} g$ to concentrate the spores. The top $9 \mathrm{ml}$ of the rinse was discarded and the remaining rinse containing the spores was distributed onto PDA in a petri plate. Excess rinse solution was poured off the PDA and the plate was allowed to dry under a flow of sterile air. After $24 \mathrm{~h}$ at $20 \mathrm{C}$, germinated spores were counted and percentage germinablity was determined.

Amount of decay of inoculated grapes treated with VPHP or water vapors was determined after holding for 4,8 , or 12 days at $10 \mathrm{C}$. Although $10 \mathrm{C}$ exceeds the optimal temperature for the postharvest storage of table grapes (Hardenburg et al., 1986), this

Table 1. Percent weight of decayed berries from noninoculated grapes flushed with water vapor $\left(\mathrm{H}_{2} \mathrm{O}\right)$ or vapor phase hydrogen peroxide $\left(\mathrm{H}_{2} \mathrm{O}_{2}\right)$ and sealed in bags for 12 days at $10 \mathrm{C}$.

\begin{tabular}{lcc}
\hline \hline & \multicolumn{2}{c}{ Decay $^{z}(\%)$} \\
\cline { 2 - 3 } Treatment & $\begin{array}{c}\text { Thompson } \\
\text { Seedless }\end{array}$ & Red Globe \\
\hline $\mathrm{H}_{2} \mathrm{O}$ & 42.4 & 59.6 \\
$\mathrm{H}_{2} \mathrm{O}_{2}$ & 11.4 & 43.2 \\
Significance & $*$ & NS
\end{tabular}

${ }^{2}$ Values represent means of two experiments for each cultivar. Each treatment was applied to three packages of grapes in each experiment.

Ns,*Nonsignificant or significant at $P<0.05$, respectively. 


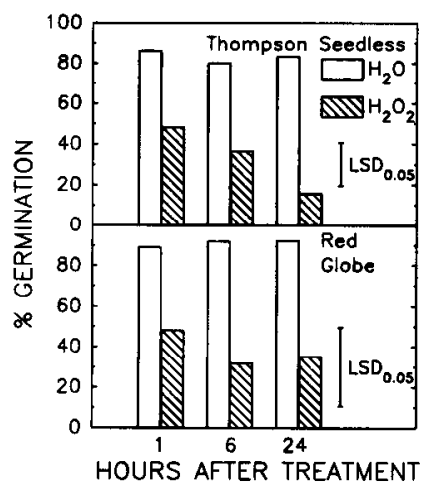

Fig. 1. Percent germination of Botrytis cinerea spores on 'Thompson Seedless' or 'Red Globe' grapes flushed with water $\left(\mathrm{H}_{2} \mathrm{O}_{2}\right)$ or hydrogen peroxide $\left(\mathrm{H}_{2} \mathrm{O}_{2}\right)$ vapors for $10 \mathrm{~min}$ at $40 \mathrm{C}$ and sealed in bags. Grapes were removed from bags 1,6 , and $24 \mathrm{~h}$ after treatment; spores were rinsed from the grapes and germinated on PDA at 20C. Bars represent mean germination of spores from six packages of grapes.

temperature accelerated decay development and facilitated the assessment of decay control, yet retarded the growth of interfering fungal pathogens, such as Rhizopus sp., or Aspergillus niger (Nelson, 1985). Bags were opened and the grape bunches weighed after each storage period. Individual grapes showing any sign of decay were removed from the bunches and weighed. The percentage of decayed berries was then calculated based on weight.

Noninoculated grapes, treated the same as inoculated grapes, were evaluated for decay, color, and soluble solids content (SSC) at 0 and 12 days following treatment. Color of three marked berries from each bunch was determined at the midpoint of the side of each berry using a Minolta Chroma Meter (model CR-200, Minolta Corp., Ramsey, N. J.) $\mathrm{O}$ and 12 days following VPHP treatment. Only nondecayed berries were evaluated. In addition, three berries were randomly chosen from each bunch and SSC was determined using a hand-held, temperaturecompensated refractometer.

Experiments, consisting of three sample bags for each treatment, time, and cultivar, were conducted twice and were subjected to analysis of variance using the General Linear Model program (SAS Institute, Cary, N.C.). Means were separated by least significant difference (LSD, $\boldsymbol{P} \leq 0.05$ ). The model was percentage decay, spore germination, SSC, or color difference as dependent variables and treatment as an independent variable with $\boldsymbol{P}<0.05$. The two cultivars were analyzed separately.

The percentage of viable Botrytis spores on inoculated 'Thompson Seedless' and 'Red Globe' grapes was significantly reduced using VPHP compared with control fruit (Fig. 1). Vapor phase hydrogen peroxide was more effective on spores on 'Thompson Seedless' grapes, where germination was reduced from $83 \%$ to $16 \%$ than in 'Red Globe' grapes, where germination of spores was reduced from $93 \%$ to $38 \%$ by $24 \mathrm{~h}$ after treatment.

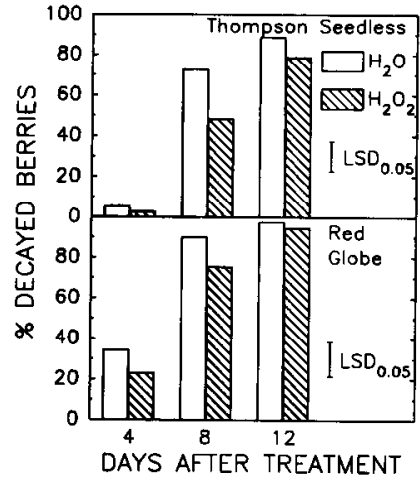

Fig. 2. Percent of decayed berries (by weight) of 'Thompson Seedless' or 'Red Globe' grapes inoculated with Botrytis cinerea spores, flushed with water $\left(\mathrm{H}_{2} \mathrm{O}_{2}\right)$ or hydrogen peroxide $\left(\mathrm{H}_{2} \mathrm{O}_{2}\right)$ vapors for $10 \mathrm{~min}$ at $40 \mathrm{C}$, and sealed in bags. Grapes were held at $10 \mathrm{C}$ and evaluated for decay 4,8 , or 12 days after treatment. Bars represent mean percentage of decay of six packages of grapes.

Mortality of spores on inoculated grapes depended on the time of exposure to the VPHP remaining in the bags following sealing. The percentage of terminable spores on inoculated 'Thompson Seedless' grapes decreased $1.7,2$, and 5.2 times 1,6 , or 24 after sealing, respectively, when compared with controls (Fig. 1). However, there were 2.7 times fewer germinable spores on inoculated 'Red Globe' grapes than on controls $6 \mathrm{~h}$ after sealing, and they did not decrease with additional holding time.

Hydrogen peroxide vapor was less effective in killing Botrytis spores on grapes than its reported efficacy on bacterial spores on plastic strips. Virtually all (99.9999\%) spores of Bacillus subtilis var. niger on plastic surface were inactivated after $10 \mathrm{~min}$ when treated with $\mathrm{H}_{2} \mathrm{O}_{2}$ vapor under conditions similar to those used here with grapes (Wang and Toledo, 1986b). Botrytis spores may be more resistant to VPHP than spores of $B$. subtilis, or the less effective control of $\mathrm{Bo}$ trytis spores on grapes in our experiment may have been a substrate effect. Grape surfaces probably have many sites for $\mathrm{H}_{2} \mathrm{O}_{2}$ to react, whereas the plastic strip used by Wang and Toledo was relatively inert. Schumb et al. (1955) found that rough surfaces were not as effectively sterilized as were smooth surfaces in seeds treated with solutions of $\mathrm{H}_{2} \mathrm{O}_{2}$. More competing reactive sites would reduce the effectiveness of peroxide against spores. The nature of the epicuticular wax found on the surface of grape berries depends on cultivar as well as growing conditions (Marois et al., 1986). The differences in the percentage of killed spores on 'Thompson Seedless' vs. 'Red Globe' grapes and differences in rates of decay may have been due to cultivar differences in the berry surfaces.

Free water on the surface of the berries may have prevented some spores from coming in contact with VPHP. Grapes sprayed with inoculum were allowed to air dry for 1 to $2 \mathrm{~h}$ before $\mathrm{H}_{2} \mathrm{O}_{2}$ treatment; however, some free moisture was still present in the interior of the bunches at the time of treatment. Following treatment," bagged grapes were kept at 10C, creating condensation in the bags and forming additional free water. This water may have prevented spore exposure to VPHP and enhanced spore germination and growth.

Vapor phase hydrogen peroxide significantly reduced decay of inoculated 'Thompson Seedless' grapes, which had 33\% fewer decayed berries 8 days after treatment than grapes treated with water vapor (Fig. 2). However, 12 days after treatment, $>75 \%$ of the berries of both treatments were rotted. 'Red Globe' grapes decayed more rapidly, having 34\% of inoculated berries decayed after 4 days of storage compared with $5 \%$ for 'Thompson Seedless'. Decay of 'Red Globe' grapes was not inhibited by VPHP treatment (Fig. 2). Decayed berries were found throughout the bunches of both cultivars and were not localized to the interior berries. In noninoculated grapes, treatments with VPHP reduced the incidence of decayed berries $73 \%$ in 'Thompson Seedless' but only $28 \%$ in 'Red Globe' when compared with controls (Table 1). Noninoculated 'Thompson Seedless' grapes treated with water vapor had $18 \%$ less decay than similarly treated 'Red Globe' grapes after 12 days at 10C.

The VPHP treatment did not affect the quality of grapes. Hydrogen peroxide is known to bleach pigments (Schumb et al., 1955); however, no bleaching of either white 'Thompson Seedless' or red 'Red Globe' was observed in our experiment. Calorimetric measurements of grapes before treatment, using the Munsell Color System, as measured with a Minolta Chroma Meter, gave value, hue angle, and chroma of 46.8, 110.8 , and 11.6 for 'Thompson Seedless' and 39.2, 359.7 , and 7.53 for 'Red Globe' grapes. Hydrogen peroxide vapor treatment had no effect on color of either cultivar by 12 days following treatment. In addition, the VPHP treatment had no significant effect on the SSC of the grapes. Before treatment, SSC of 'Thompson Seedless' and 'Red Globe' grapes averaged $21.8 \%$ and $18.4 \%$, respectively, and it decreased to $18.4 \%$ and $17.2 \%$ after 12 days at $10 \mathrm{C}$.

The results from this study indicate that VPHP has potential for control of postharvest decay of grapes. Hydrogen peroxide vapors reduced the terminability of Botrytis cinerea spores, inhibited berry decay, and had no detrimental effect on berry quality. Hydrogen peroxide degrades into $\mathrm{O}_{2}$, and $\mathrm{H}_{2} \mathrm{O}_{2}$ leaving no harmful residue and is considered a generally-recognized-as-safe (GRAS) compound by the Food and Drug Administration. Additional work needs to be done to determine the optimum treatment conditions and procedures to maximize decay control under conditions that prevail during normal storage and marketing of grapes.

\section{Literature Cited}

Federal Registry. 1986. GRAS status of sulfiting agents for use on fresh and frozen foods revoked. Federal Registry 51:25021.

Federal Registry. 1989. Pesticide tolerance for 
sulfur dioxide. Federal Registry 54:2012520126.

Hardenburg, R.E., A.E. Watada, and C.Y. Wang. 1986. The commercial storage of fruits, vegetables, and florist and nursery stocks. U.S. Dept. Agr. Hdbk. 66.

Harvey, J.M. and M. Uota. 1978. Table grapes and refrigeration: Fumigation with sulfur dioxide. Intl J. Refrigeration 1:167-171.

Ito, K. A., C.B. Denny, C.K. Brown, M. Yao, and M.L. Seeger. 1973. Resistance of bacterial spores to hydrogen peroxide. Food Technol. 27(11):58-66.

Klapes, N.A. and D. Vesley. 1990. Vapor-phase hydrogen peroxide as a surface decontaminant and sterilant. Applied Environ. Microbiol. 56(2):503-506.

Marois, J. J., J.K. Nelson, J.C. Morrison, L.S. Lile, and A.M. Bledsoe. 1986. The influence of berry contact within grape clusters on the development of Botrytis cinerea and epicuticular wax. Amer. J. Enol. Vitic. 37(4):293296.

Nelson, K.E. 1983. Effects of in-package sulfur dioxide generators, package liners, and temperature on decay and desiccation of table grapes. Amer. J. Enol. Vitic. 34:10-16

Nelson, K.E. 1985. Harvesting and handling California table grapes for market. Univ. Calif. Bul. 1913.

Schumb, W. C., C.N. Satterfield, and R.L. Wentworth. 1955. Hydrogen peroxide. Reinhold, New York.

Smilanick, J.L., J.M. Harvey, P.L. Hartsell, C.M. Harris, D.C. Fouse, and M. Assemi. 1990. Influence of sulfur dioxide fumigant dose on residues and control of postharvest decay of grapes. Plant Dis. 74(6):418-421.

Smith, Q.J. and K.L. Brown. 1980. The resistance of dry spores of Bacillus subtilis var. glo- bigii (NCIB 8058) to solutions of hydrogen peroxide in relation to aseptic packaging. J. Food Technol 15:169-179.

Toledo, R.T. 1988. Overview of sterilization methods for aseptic packaging materials. A.C.S. Symp. Ser., Amer. Chem. Soc., Washington, D.C, p. $94-108$.

von Bockelmann, L and B. von Bockelmann. 1972. The sporicidal action of hydrogen peroxide-a literature review. Lebensmittel-Wissenschaft \& Technol 5:221-225.

Wang, J. and R.T. Toledo. 1986a. Inactivation of microorganisms on polyethylene exposed to hydrogen peroxide vapors in air at various temperatures, p. 37-48. In: M.L. Troedel (cd.) ASTMP STP 912. Amer. Soc. Testing Materials, Philadelphia.

Wang, J. and R.T. Toledo. 1986b. Sporicidal properties of mixtures of hydrogen peroxide vapor and hot air. Food Technol. 40(12):60-67. 